\title{
Determination of the morphological differences between males and females in populations of goldfish Tyumen region Yankova N. ${ }^{1}$, Sidorova M. ${ }^{2}$ \\ Определение морфологических различий между самками и самцами в популяциях серебряного карася Тюменской области Янкова Н. В. ${ }^{1}$, Сидорова М. И. ${ }^{2}$
}

\author{
${ }^{1}$ Янкова Наталья Васильевна / Yankova Natalya - кандидат биологических наук, старший научный сотрудник, \\ Госрыбиентр \\ доиент, \\ кафедра водных биоресурсов и аквакультуры, \\ Институт биотехнологии и ветеринарной медицины, \\ Государственный аграрный университет Северного Зауралья; \\ ${ }^{2}$ Сидорова Мария Ивановна / Sidorova Mагуа - младший научный сотрудник, \\ Госрыбиентр, \\ аспирант, \\ кафедра водных биоресурсов и аквакультуры, \\ Институт биотехнологии и ветеринарной медицины, \\ Государственный аграрный университет Северного Зауралья, г. Тюмень
}

\begin{abstract}
Аннотация: при анализе выборки серебряного карася выявлено в зависимости от условий обитания и объема сравниваемых выборок от одного до восьми достоверно различаюшихся морфометрических показателей у самок и самиов. Чаще всего у самиов длиннее спинной и грудные плавники. Есть основания разработать методику определения пола у серебряного карася по морфологическим признакам.

Abstract: analyzing a sample of goldfish, identified depending on habitat conditions and volume compared samples from one to eight significantly different morphometric parameters in males and females. More often than males longer dorsal and pectoral fins. There is every reason to develop a method for determining the sex of a goldfish on morphological characteristics.
\end{abstract}

Ключевые слова: серебряный карась, морфометрический анализ, половой диморфизм. Keywords: goldfish, morphometric analysis, sexual dimorphism.

УДК 597 - 14.087: 597.554.3 (571. 12)

Изучение внутрипопуляционной структуры естественной ихтиофауны является актуальным пунктом исследований в современной аквакультуре и рыболовстве. Серебряный карась Carassius auratus sensu lato (L., 1782) остается одним из наиболее распространенных пресноводных видов карповых рыб Евроазиатского континента и в частности Западной Сибири [3]. Западная Сибирь очень богата озерами, большая их часть находится на юге Тюменской области. Основным представителем ихтиофауны в этих озерах, особенно связанных с речной системой, является серебряный карась [13].

Данный вид характеризуется широкой экологической пластичностью и адаптацией к разнообразным условиям среды. Он способен длительный период времени переживать низкое содержание растворенного кислорода в воде, поэтому наиболее распространен в заморных водоемах, где большая часть других представителей ихтиофауны погибает. Известно, что соотношение полов у данного вида варьирует в широком диапазоне в связи с гиногенетическим способом размножения [7]. В последние годы во многих регионах, включая и Тюменскую область, наблюдается увеличение численности серебряного карася при снижении золотого $[2,4,11,14]$. В последние годы получены данные о естественной гибридизации золотого и серебряного карасей в естественных ареалах $[8,11]$. При этом выявлено, что диплоиды и триплоиды серебряного карася морфологически различаются $[1,5,14]$. По определению пола на основе анализа морфометрических признаков у серебряного карася имеется только одна публикация [15]. В литературных источниках имеются различные данные о определении пола на основе дискриминантного анализа морфологических признаков в популяциях других видов рыб. В частности, есть разработки по определению пола на основе дискриминантного анализа морфологических признаков у белого толстолобика [6] и русского осетра [9]. Данных по этой теме по карповым рыбам явно недостаточно, поэтому актуально проводить исследования для понимания принципов формирования генетической и половой структуры вида.

Целью исследования явилось изучение различий морфологических признаков у самок и самцов в популяциях серебряного карася Тюменской области.

Материал и методика исследования. Материал для исследований собирался на территории Тюменской области в летний период времени (июнь-июль) с трех разнотипных водных объектов (замкнутое заморное озеро Мостовое; незаморное озеро Кучак, сообщающееся с другими водоемами и река Тобол). Ихтиологический материал подвергали морфометрическому анализу [12]. Были 
проанализированы длина рыбы без хвостового плавника или промысловая длина $(l)$ и другие 23 пластических промера, выраженные в системе индексов: длина головы $(C)$, максимальная высота тела $(H)$, минимальная высота тела $(h)$, длина основания спинного плавника $(l D)$, высота спинного плавника $(h D)$, антедорсальное расстояние $(a D)$, постдорсальное расстояние $(p D)$, длина хвостового стебля $(p l)$, длина основания анального плавника $(l A)$, высота анального плавника $(h A)$, антеанальное расстоянием $(a A)$, антепектральное расстояние $(a P)$, антевентральное расстояние $(a V)$, пектовентральное расстояние $(P V)$, вентроанальное расстояние $(V A)$, длина грудного плавника $(l P)$, длина брюшного плавника $(l V)$, ширина тела $(t t)$, ширина лба $(i o)$, длина рыла $(r)$, диаметр глаза $(o)$, заглазничное пространство (po), высота головы у затылка $(h C)$. Статистический анализ отношений морфометрических различий между самками и самцами проводился с расчетом среднего значения (х), стандартного отклонения $(\sigma)$, ошибки средней $\left(\mathrm{m}_{\mathrm{X}}\right)$, коэффициента вариации $(\mathrm{CV})$. Достоверность различий полученных результатов оценивали по Критерию Стьюдента $\left(\mathrm{T}_{\mathrm{st}}\right)$ для малых и разновеликих выборок. Затем проводилось сравнение данных между всеми выбранными водными объектами.

Результаты исследования. В популяции серебряного карася р. Тобол в июне 2015 г. выявлен всего один достоверно различающийся морфологический признак между самками и самцами - длина основания анального плавника $(l A)$. Вероятно, это обусловлено крайне малым объемом выборки самцов всего 2 из 87 исследованных рыб (таблица 1).

Таблица 1. Морфометрические признаки серебряного карася р. Тобол, Тюменский район

\begin{tabular}{|c|c|c|c|c|c|c|c|c|c|c|c|}
\hline \multirow{2}{*}{ Признак } & \multicolumn{3}{|c|}{$\begin{array}{c}\text { Все самки }+ \\
(85 \text { экз. })\end{array}$} & \multicolumn{3}{|c|}{$\begin{array}{c}\text { Все самцы } \hat{\sigma} \\
(2 \text { экз. })\end{array}$} & \multirow{2}{*}{$\begin{array}{c}\text { Tst все } \\
+\mathbf{~} \\
+ \text { все }{ }^{\lambda}\end{array}$} & \multicolumn{3}{|c|}{$\begin{array}{c}\text { Самки 14,5-15,5 см (38 } \\
\text { экз.) }\end{array}$} & \multirow{2}{*}{$\begin{array}{c}\text { Tst } q \\
14,5- \\
15,5 \text { cм } \\
\text { и все } \delta\end{array}$} \\
\hline & 1 & 2 & 3 & 1 & 2 & 3 & & 1 & 2 & 3 & \\
\hline$l, \mathrm{~cm}$ & 15,53 & 0,10 & 6,20 & 15,13 & 0,41 & 3,83 & 0,58 & 15,22 & 0,04 & 1,70 & 0,43 \\
\hline$m, \Gamma$ & 117,4 & 2,7 & 21,4 & 97,6 & 7,8 & 11,3 & 1,10 & 111,6 & 3,0 & 16,4 & 1,05 \\
\hline$r, \%$ om $C$ & 29,09 & 0,31 & 9,81 & 28,87 & 0,41 & 2,01 & 0,11 & 29,29 & 0,41 & 8,71 & 0,22 \\
\hline$o, \%$ om $C$ & 21,12 & 0,28 & 12,37 & 19,86 & 1,05 & 7,47 & 0,67 & 21,27 & 0,31 & 9,10 & 0,99 \\
\hline $\begin{array}{c}\text { po, } \% \text { om } \\
C\end{array}$ & 54,41 & 0,43 & 7,24 & 55,49 & 1,44 & 3,67 & 0,38 & 54,33 & 0,63 & 7,17 & 0,41 \\
\hline $\begin{array}{c}\text { io, } \% \text { om } \\
C\end{array}$ & 38,20 & 0,34 & 8,17 & 36,90 & 2,14 & 8,21 & 0,58 & 38,93 & 0,41 & 6,56 & 1,06 \\
\hline $\begin{array}{c}h C, \% \text { om } \\
C\end{array}$ & 86,49 & 0,60 & 6,41 & 87,27 & 4,40 & 7,13 & 0,19 & 86,62 & 0,86 & 6,09 & 0,16 \\
\hline$t t, \%$ om $C$ & 57,08 & 0,62 & 9,97 & 57,74 & 1,31 & 3,21 & 0,16 & 56,71 & 0,94 & 10,26 & 0,24 \\
\hline C, \% om $l$ & 28,79 & 0,20 & 6,46 & 27,00 & 0,03 & 0,15 & 1,35 & 28,92 & 0,30 & 6,45 & 1,42 \\
\hline H, \% om l & 37,28 & 0,18 & 4,38 & 37,02 & 0,14 & 0,55 & 0,23 & 37,27 & 0,26 & 4,33 & 0,21 \\
\hline h,\%om l & 14,71 & 0,12 & 7,46 & 14,39 & 0,54 & 5,26 & 0,40 & 14,71 & 0,16 & 6,53 & 0,44 \\
\hline $\begin{array}{c}a D, \% \text { om } \\
l\end{array}$ & 52,40 & 0,30 & 5,25 & 49,27 & 0,09 & 0,25 & 1,59 & 52,76 & 0,41 & 4,80 & 1,90 \\
\hline $\begin{array}{c}a P, \% \text { om } \\
l\end{array}$ & 30,12 & 0,21 & 6,48 & 28,78 & 0,31 & 1,53 & 0,96 & 30,37 & 0,34 & 6,91 & 1,04 \\
\hline $\begin{array}{c}p D, \% \text { om } \\
l\end{array}$ & 22,51 & 0,20 & 8,25 & 22,50 & 1,44 & 9,05 & 0,01 & 22,39 & 0,32 & 8,74 & 0,08 \\
\hline $\mathrm{pl}, \%$ om l & 19,17 & 0,20 & 9,61 & 16,97 & 0,49 & 4,11 & 1,67 & 19,30 & 0,29 & 9,19 & 1,81 \\
\hline $\begin{array}{c}l D, \% \text { om } \\
l\end{array}$ & 36,72 & 0,26 & 6,45 & 34,25 & 0,63 & 2,58 & 1,45 & 37,16 & 0,38 & 6,29 & 1,70 \\
\hline $\begin{array}{c}h D, \% \text { om } \\
l\end{array}$ & 18,14 & 0,18 & 8,91 & 17,76 & 0,45 & 3,57 & 0,33 & 18,22 & 0,24 & 8,04 & 0,43 \\
\hline$l A, \%$ om $l$ & 11,57 & 0,13 & 9,99 & 14,78 & 3,43 & 32,85 & $3,26 * *$ & 11,63 & 0,18 & 9,71 & $2,73 *$ \\
\hline $\begin{array}{c}\mathrm{hA}, \% \mathrm{om} \\
l\end{array}$ & 15,13 & 0,12 & 7,15 & 14,74 & 0,00 & 0,03 & 0,50 & 15,44 & 0,16 & 6,23 & 1,00 \\
\hline$l P, \%$ om $l$ & 18,14 & 0,16 & 8,14 & 18,99 & 1,73 & 12,90 & 0,77 & 18,18 & 0,28 & 9,37 & 0,62 \\
\hline $\mathrm{lV}, \%$ om $\mathrm{l}$ & 19,20 & 0,15 & 7,28 & 17,95 & 1,35 & 10,60 & 1,23 & 19,14 & 0,23 & 7,52 & 1,09 \\
\hline $\begin{array}{c}a V, \% \text { om } \\
l\end{array}$ & 49,44 & 0,31 & 5,78 & 46,54 & 1,49 & 4,54 & 1,41 & 49,67 & 0,48 & 5,92 & 1,45 \\
\hline $\begin{array}{c}a A, \% \text { om } \\
l \\
\end{array}$ & 77,17 & 0,98 & 11,75 & 77,07 & 0,04 & 0,07 & 0,02 & 78,67 & 0,63 & 4,91 & 0,57 \\
\hline $\begin{array}{c}P V, \% \text { om } \\
l\end{array}$ & 21,40 & 0,18 & 7,68 & 19,69 & 0,06 & 0,44 & 1,45 & 21,37 & 0,20 & 5,88 & 1,84 \\
\hline $\begin{array}{c}A, \% \text { om } \\
l\end{array}$ & 31,65 & 0,30 & 8,78 & 32,86 & 0,36 & 1,56 & 0,61 & 31,42 & 0,38 & 7,41 & 0,85 \\
\hline & & & & 5 & 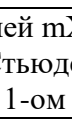 & $3-$ & da & 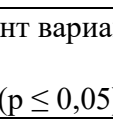 & & & \\
\hline
\end{tabular}


** различия достоверны на 2-ом уровне значимости $(\mathrm{p} \leq 0,01)$

В выборке из уловов оз. Кучаково, собранной в июне-июле 1997 г. и 2000 г., выявлены четыре достоверно различающихся морфологических признака между полами - длина основания спинного плавника, длина грудного плавника, антевентральное расстояние и вентроанальное расстояние (таблица 2).

Таблица 2. Морфометрические признаки серебряного карася оз. Кучаково, Нижнетавдинский район Тюменской области

\begin{tabular}{|c|c|c|c|c|c|c|c|c|c|c|c|}
\hline \multirow{2}{*}{ Признак } & \multicolumn{3}{|c|}{$\begin{array}{c}\text { Все самки }+ \\
(44 \text { экз. }) \\
\end{array}$} & \multicolumn{3}{|c|}{$\begin{array}{c}\text { Все самцы } \\
(11 \text { экз.) }\end{array}$} & \multirow{2}{*}{$\begin{array}{c}\text { Tst все } \\
+ \text { и } \\
\text { все } \delta\end{array}$} & \multicolumn{3}{|c|}{$\begin{array}{c}\text { Одноразмерные самки } \\
\text { (27 экз.) } \\
\end{array}$} & \multirow{2}{*}{$\begin{array}{c}\text { Tst } \odot \\
15,0- \\
25,5 \text { cm } \\
\text { и все }\end{array}$} \\
\hline & 1 & 2 & 3 & 1 & 2 & 3 & & 1 & 2 & 3 & \\
\hline$l, \mathrm{~cm}$ & 22,34 & 0,93 & 27,64 & 19,75 & 1,25 & 20,92 & 1,29 & 18,91 & 0,62 & 17,09 & 0,65 \\
\hline$m, \Gamma$ & 543,8 & 63,7 & 77,8 & 314,6 & 60,3 & 63,6 & 1,72 & 286,8 & 30,0 & 54,4 & 0,44 \\
\hline$r, \%$ om $C$ & 30,50 & 1,11 & 24,05 & 33,58 & 1,47 & 14,57 & 1,30 & 29,35 & 1,72 & 30,45 & 1,44 \\
\hline o, \% om $C$ & 18,32 & 0,42 & 15,06 & 19,92 & 1,31 & 21,79 & 1,49 & 18,75 & 0,56 & 15,57 & 0,94 \\
\hline $\begin{array}{c}\text { po, } \% \text { om } \\
C\end{array}$ & 49,98 & 0,89 & 11,87 & 53,97 & 3,72 & 22,85 & 1,52 & 48,49 & 1,35 & 14,47 & 1,68 \\
\hline io, \% om C & 41,30 & 0,43 & 6,95 & 41,49 & 2,34 & 18,70 & 0,13 & 41,54 & 0,53 & 6,68 & 0,03 \\
\hline $\begin{array}{c}\text { hC, \% om } \\
C\end{array}$ & 89,37 & 1,25 & 9,26 & 92,06 & 5,55 & 19,98 & 0,71 & 90,63 & 1,62 & 9,31 & 0,32 \\
\hline$t t, \%$ om $C$ & 71,63 & 1,29 & 11,98 & 66,11 & 4,04 & 20,29 & 1,65 & 68,41 & 1,36 & 10,29 & 0,67 \\
\hline C, \% om l & 27,34 & 0,26 & 6,39 & 26,49 & 1,07 & 13,38 & 1,11 & 27,82 & 0,27 & 5,05 & 1,61 \\
\hline H, \% om l & 46,10 & 0,53 & 7,66 & 44,82 & 0,55 & 4,09 & 1,15 & 46,32 & 0,66 & 7,43 & 1,34 \\
\hline$h, \%$ om l & 16,82 & 0,22 & 8,60 & 16,81 & 0,35 & 6,99 & 0,02 & 16,71 & 0,32 & 9,88 & 0,17 \\
\hline$a D, \%$ om l & 52,01 & 0,54 & 6,87 & 51,86 & 0,61 & 3,90 & 0,13 & 52,56 & 0,56 & 5,49 & 0,72 \\
\hline$a P, \%$ om l & 28,61 & 0,23 & 5,42 & 29,07 & 0,33 & 3,77 & 0,91 & 28,99 & 0,26 & 4,71 & 0,15 \\
\hline$p D, \%$ om $l$ & 16,44 & 0,27 & 11,00 & 17,02 & 0,48 & 9,29 & 0,95 & 16,52 & 0,35 & 10,87 & 0,78 \\
\hline $\mathrm{pl}, \%$ om l & 21,77 & 0,43 & 13,21 & 21,82 & 0,70 & 10,59 & 0,06 & 21,04 & 0,52 & 12,91 & 0,82 \\
\hline$l D, \%$ om $l$ & 37,12 & 0,38 & 6,87 & 39,40 & 0,56 & 4,70 & $2,74 * *$ & 37,04 & 0,55 & 7,68 & $2,48 *$ \\
\hline hD, \% om l & 17,32 & 0,26 & 10,04 & 17,64 & 0,27 & 5,10 & 0,58 & 17,11 & 0,36 & 11,00 & 0,86 \\
\hline$l A, \%$ om $l$ & 12,19 & 0,21 & 11,18 & 12,79 & 0,28 & 7,35 & 1,37 & 12,46 & 0,20 & 8,43 & 0,88 \\
\hline$h A, \%$ om l & 17,17 & 0,28 & 10,76 & 17,75 & 0,42 & 7,87 & 0,95 & 17,54 & 0,36 & 10,62 & 0,32 \\
\hline$l P, \%$ om $l$ & 18,40 & 0,31 & 11,34 & 19,81 & 0,42 & 7,09 & $2,09 *$ & 18,19 & 0,44 & 12,48 & $2,15 *$ \\
\hline$l V, \%$ om $l$ & 21,08 & 0,33 & 10,26 & 21,49 & 0,40 & 6,19 & 0,59 & 21,22 & 0,50 & 12,21 & 0,31 \\
\hline$a V, \%$ om l & 48,83 & 0,34 & 4,57 & 47,89 & 0,51 & 3,56 & 1,29 & 49,12 & 0,31 & 3,23 & $2,07 *$ \\
\hline$a A, \%$ om l & 79,33 & 1,26 & 10,56 & 75,94 & 0,79 & 3,43 & 1,30 & 78,77 & 1,17 & 7,71 & 1,45 \\
\hline$P V, \%$ om l & 22,33 & 0,23 & 6,95 & 21,36 & 0,33 & 5,12 & 1,93 & 22,07 & 0,25 & 5,93 & 1,57 \\
\hline$V A, \%$ om l & 33,32 & 0,32 & 6,31 & 31,98 & 0,29 & 2,96 & $2,02 *$ & 32,92 & 0,32 & 5,13 & 1,70 \\
\hline
\end{tabular}

В выборках серебряного карася из оз. Мостовое, исследованных в июне-июле 1997-2000 гг., выявлено максимальное число достоверных различий самок и самцов - восемь морфологических признаков на разных уровнях значимости: длина основания спинного плавника, максимальная высота тела, высота анального плавника, длина грудного плавника, длина брюшного плавника, ширина тела, ширина лба, длина рыла (таблица 3).

Таблииа 3. Морфометрические признаки серебряного карася оз. Мостовое, Тюменский район

\begin{tabular}{|c|c|c|c|c|c|c|c|c|c|c|c|}
\hline \multirow{2}{*}{ Признак } & \multicolumn{3}{|c|}{$\begin{array}{c}\text { Все самки } q \\
(44 \text { экз.) } \\
\end{array}$} & \multicolumn{3}{|c|}{$\begin{array}{c}\text { Все самцы }{ }^{\hat{\alpha}} \\
(5 \text { экз. })\end{array}$} & \multirow{2}{*}{$\begin{array}{c}\text { Tst все } \\
+ \text { и } \\
\text { все } \hat{\sigma}\end{array}$} & \multicolumn{3}{|c|}{$\begin{array}{c}\text { Одноразмерные самки } \\
(29 \text { экз.) }\end{array}$} & \multirow{2}{*}{$\begin{array}{c}\text { Tst }+ \\
13,9- \\
17,0 \text { см } \\
\text { и все } \frac{\partial}{0}\end{array}$} \\
\hline & 1 & 2 & 3 & 1 & 2 & 3 & & 1 & 2 & 3 & \\
\hline$l, \mathrm{~cm}$ & 14,67 & 0,36 & 16,47 & 15,94 & 0,53 & 7,43 & 1,14 & 15,37 & 0,17 & 5,97 & 1,18 \\
\hline$m, \Gamma$ & 100,5 & 1,9 & 12,8 & 76,0 & 0,7 & 2,1 & $4,17 * * *$ & 106,0 & 1,6 & 8,0 & $7,62 * * *$ \\
\hline$r, \%$ om $C$ & 25,21 & 0,39 & 10,38 & 23,02 & 1,29 & 12,54 & \begin{tabular}{|l|}
1,72 \\
\end{tabular} & 25,81 & 0,48 & 10,11 & $2,11^{*}$ \\
\hline$o, \%$ om $C$ & 19,89 & 0,26 & 8,62 & 20,67 & 0,29 & 3,14 & 0,98 & 19,84 & 0,32 & 8,72 & 1,03 \\
\hline $\begin{array}{c}\text { po, \% om } \\
\text { C }\end{array}$ & 56,69 & 0,38 & 4,41 & 54,28 & 1,77 & 7,28 & 1,86 & 56,69 & 0,44 & 4,21 & 1,80 \\
\hline io, \% om $C$ & 42,68 & 0,43 & 6,70 & 39,89 & 1,16 & 6,48 & $2,04 *$ & 42,82 & 0,54 & 6,85 & $2,04 *$ \\
\hline $\begin{array}{c}\text { hC, \% om } \\
C\end{array}$ & 95,39 & 0,92 & 6,39 & 91,84 & 4,06 & 9,88 & 1,14 & 95,52 & 0,78 & 4,38 & 1,42 \\
\hline $\mathrm{tt}, \% \mathrm{om} C$ & 72,76 & 0,92 & 8,37 & 63,33 & 1,58 & 5,58 & $3,33 * *$ & 73,92 & 1,10 & 7,99 & $3,78 * * *$ \\
\hline C, \% om l & 26,30 & 0,21 & 5,28 & 26,14 & 0,33 & 2,84 & 0,26 & 25,94 & 0,21 & 4,43 & 0,36 \\
\hline
\end{tabular}




\begin{tabular}{|c|c|c|c|c|c|c|c|c|c|c|c|}
\hline H, \% om l & 39,86 & 0,37 & 6,17 & 37,44 & 1,23 & 7,36 & $2,02 *$ & 39,86 & 0,49 & 6,56 & 1,84 \\
\hline$h, \%$ om $l$ & 14,69 & 0,10 & 4,54 & 15,06 & 0,08 & 1,15 & 1,20 & 14,62 & 0,10 & 3,86 & 1,66 \\
\hline$a D, \%$ om $l$ & 49,69 & 0,37 & 4,95 & 47,81 & 0,47 & 2,18 & 1,66 & 49,37 & 0,36 & 3,91 & 1,71 \\
\hline$p D, \%$ om l & 22,82 & 0,25 & 7,27 & 23,49 & 0,65 & 6,19 & 0,85 & 22,96 & 0,28 & 6,59 & 0,71 \\
\hline $\mathrm{pl}, \%$ om l & 17,67 & 0,18 & 6,64 & 18,11 & 0,35 & 4,29 & 0,80 & 17,76 & 0,23 & 6,99 & 0,58 \\
\hline$l D, \%$ om l & 34,56 & 0,32 & 6,23 & 36,91 & 1,17 & 7,08 & $2,21 *$ & 34,34 & 0,36 & 5,60 & $2,53 *$ \\
\hline$h D, \%$ om $l$ & 16,51 & 0,22 & 8,79 & 17,25 & 0,82 & 10,65 & 1,02 & 16,31 & 0,28 & 9,38 & 1,20 \\
\hline$l A, \%$ om $l$ & 11,60 & 0,14 & 7,81 & 11,65 & 0,34 & 6,57 & 0,11 & 11,50 & 0,15 & 7,12 & 0,37 \\
\hline$h A, \%$ om l & 14,67 & 0,21 & 9,40 & 16,64 & 0,70 & 9,36 & $2,93 * *$ & 14,85 & 0,25 & 9,17 & $2,57 *$ \\
\hline$l P, \%$ om l & 18,77 & 0,29 & 10,16 & 20,56 & 0,66 & 7,17 & 1,99 & 18,92 & 0,30 & 8,55 & $2,06 *$ \\
\hline$l V, \%$ om $l$ & 19,39 & 0,23 & 7,84 & 21,60 & 0,55 & 5,68 & $3,06 * *$ & 19,70 & 0,24 & 6,60 & $2,96 * *$ \\
\hline$a V, \%$ om $l$ & 49,31 & 0,31 & 4,14 & 47,60 & 0,41 & 1,95 & 1,82 & 49,20 & 0,41 & 4,44 & 1,57 \\
\hline$a A, \%$ om $l$ & 75,45 & 0,55 & 4,83 & 73,14 & 0,80 & 2,45 & 1,37 & 75,97 & 0,61 & 4,29 & 1,83 \\
\hline$P V, \%$ om l & 22,54 & 0,25 & 7,35 & 21,20 & 0,74 & 7,77 & 1,68 & 22,67 & 0,33 & 7,77 & 1,68 \\
\hline$V A, \%$ om l & 31,77 & 0,26 & 5,41 & 32,10 & 0,30 & 2,09 & 0,42 & 31,75 & 0,34 & 5,71 & 0,42 \\
\hline \multicolumn{12}{|c|}{$\begin{array}{c}\text { Примечания: } 1 \text { - средняя Хcp., } 2 \text { - ошибка средней } \mathrm{mXcp.,} 3 \text { - коэффициент вариации } \mathrm{CV} ; \\
\text { Tst - критерий Стьюдента; } \\
\text { * - различия достоверны на } 1 \text {-ом уровне значимости }(\mathrm{p} \leq 0,05) ; \\
\text { ** - различия достоверны на 2-ом уровне значимости }(\mathrm{p} \leq 0,01) ; \\
\text { *** - различия достоверны на } 3 \text {-м уровне значимости }(\mathrm{p} \leq 0,001)\end{array}$} \\
\hline
\end{tabular}

Сравнивая данные по трем разнотипным водным объектам, отмечаем, что для всех трех выборок нет общих различающихся признаков. При сравнении озерных популяций обнаружено два общих морфологических отличия: у самцов длиннее спинной и грудные плавники.

Таким образом, у серебряного карася даже на минимальном объеме сравниваемых выборок самок и самцов в речной популяции, а также по значительно большему числу признаков в озерных популяциях, обнаружены достоверные морфологические различия. Основные отличия, как отмечалось и другими исследователями карповых рыб, проявляются в большей длине плавников у самцов. Это позволяет приступить к разработке методики определения пола у карповых рыб на примере серебряного карася по морфометрическим показателям, как на неживом материале, так, в дальнейшем, и на живых объектах. Важно то, что в зависимости от экологических условий, проявления полового диморфизма могут очень сильно варьировать.

\section{Лumepamypa}

1. Абраменко М. И. Дифференциальная избирательность самцов серебряного карася Carassius auratus gibelio при брачном ухаживании за самками бисексуальной и гиногенетической форм // Первый конгресс ихтиологов России: Тез. докл. (Астрахань, сентябрь 1997 г.). М.: ВНИРО, 1997. С. 185.

2. Абраменко М.И., Кравченко О.В., Великоиваненко А.Е. Генетическая структура популяций в диплоидно-триплоидном комплексе серебряного карася Carassius auratus gibelio в бассейне Нижнего Дона // Вопр. Ихтиологии, 1997. Т. 37. № 1. С. 62-71.

3. Аннотированный каталог круглоротых и рыб континентальных вод России. М., 1998. 220 с.

4. Бакина А. В., Янкова Н. В., Петрачук Е. С., Шнайдер М. В., Таскаева К. Р. Современное состояние популяции золотого карася Carassius carassius (L, 1758) озера Андреевское Тюменского района // Молодой ученый, 2015. № 6.5. С. 155-158.

5. Васильева Е.Д. О морфологической дивергенции гиногенетической и бисексуальной форм серебряного карася Carassius auratus (Cyprinidae, Pisces) // Зоологический журнал, 1990. Т. 69. № 11. C. $97-110$.

6. Волчков Ю.А., Решетников С.И., Илясова В.А. и др. Методические указания по оценке темпа полового созревания растительноядных рыб. М.: ВНИИПРХ, 1990. 33 с.

7. Головинская К. А., Ромашов Д. Д., Черфас Н. Б. Однополые и двуполые формы серебряного карася (Carassius auratus gibelio (Bloch)) // Вопр. Ихтиологии, 1965. Т. 5. Вып. 4. С. 614-629.

8. Кокодий C. В. Естественная гибридизация золотого карася Carassius carassius (L., 1758) с серебряным C. auratus (L., 1758) s. lato в бассейне Днепра // Автореф. дис. ...канд. биол. наук. Киев, 2010. 27 с.

9. Мальцев А. В., Меркулов Я. Г. Биометрический метод определения пола осетровых, в частности русского осетра Acipenser gueldenstaedtii (Acipenseridae) Азовской популяции // Вопр. Ихтиологии, 2006. T. 46. № 4. C. 536-540.

10. Медведев В.И. Морфобиологические особенности бисексуальных и гиногенетических популяций карасей озер Урала и циклические колебания их уловов: Дис.... канд. биол. наук. Свердловск, 1976. $227 \mathrm{c.}$

11. Межжерин С. В., Кокодий С. В., Кулиш А. В., Верлатый Д. Б., Федоренко Л. В. Гибридизация золотого карася (Carassius carassius (Linnaeus, 1758)) в водоёмах Украины и генетическая структура 
гибридов // Цитология и генетика, 2012. 46. № 1. С. 37-46.

12. Правдин И. Ф. Руководство по изучению рыб. Москва, 1966. 376 с.

13. Экология рыб Обь-Иртышского бассейна. М.: Товарищество научных изданий КМК, 2006. 596 с.

14.Янкова Н. В. Эколого-морфологические особенности диплоидно-триплоидных комплексов серебряного карася Carassius auratus gibelio (Bloch) на примере озер междуречья Тобол-Тавда: автореф. дис. ... канд. биол. наук. Тюмень, 2006. 22 с.

15. Янкова Н. В., Шивторова О. Э., Бакина А. В. Определение пола методом дискриминантного анализа по морфометрическим признакам у серебряного карася // Актуальные проблемы современной науки. Материалы трудов участников 12-й международной телеконференции. Том 2. № 3. Томск, 2013. С. $132-133$ 